\title{
Behavioral factors influencing partner trust in logistics collaboration: a review
}

\author{
Morice Daudi $^{1} \cdot$ Jannicke Baalsrud Hauge $^{2,3} \cdot$ Klaus-Dieter Thoben $^{1,2}$
}

Received: 23 December 2015/ Accepted: 10 August 2016/Published online: 27 August 2016

(C) The Author(s) 2016. This article is published with open access at Springerlink.com

\begin{abstract}
Logistics collaboration has emerged a prevalent strategy to mitigate challenge individuals and organizations encounter. A successful collaboration, however, depends on certain trustworthy behaviors partner exhibit. To that end, understanding aspects constituting behavioral uncertainty and mechanisms by which such aspects affect partner trust is a necessary. This necessity counts on emergent behavioral trust uncertainties, constituted by partner's actions and interactions occurring during collaboration. While this is a necessary requirement, most of the studies in the literature lack to take into account the influence of behavioral uncertainty on collaboration and partner trust. To that effect, this paper uncovers outlined limitation by establishing behavioral factors influencing partner trust in operational stage of logistics collaboration. To accomplish this objective, a systematic literature review (SLR) is deployed to consolidate research domains of logistics, supply chain, collaboration, and trust. SLR proceeds by
\end{abstract}

This article is part of a focus collection on "Dynamics in Logistics: Digital Technologies and Related Management Methods".

Morice Daudi

mdaudi@uni-bremen.de

Jannicke Baalsrud Hauge

baa@biba.uni-bremen.de

Klaus-Dieter Thoben

tho@biba.uni-bremen.de

1 International Graduate School for Dynamics in Logistics (IGS), University of Bremen, c/o BIBA GmbH,

Hochschulring 20, 28359 Bremen, Germany

2 Bremer Institut für Produktion und Logistik, University of Bremen, Bremen, Germany

3 School of Technology and Health, KTH, Royal Institute of Technology, Stockholm, Sweden defining a review protocol, followed by a search process conducted in 5 databases using 20 search terms on articles published between 2001 and 2015 inclusively. Among findings this SLR has revealed are four behavioral factors and thirteen criteria proposed to affect partner trust. Additionally, these factors constitute success and measurable criteria needed for empirical investigation which may employ experimental and/or case-study methods. Moreover, synthesized factors extend further an understanding of behavioral trust in ad hoc collaborative networks, a large part of which being supported by networks of humans and computers.

Keywords Trust · Partner trust · Resource sharing · Behavioral trust · Logistics collaboration

\section{Introduction}

Nowadays, logistics collaboration has emerged a strategy individuals and organizations apply to gain benefits which they can hardly achieve when working individually. In particular, logistics collaboration helps to mitigate most inefficiencies managers encounter in their daily undertakings. Such inefficiencies include poor capacity utilization, empty backhaul, high transport costs, low-profit margins, and harsh environmental impacts [1]. Equally, according to Wang and Kopfer [2], logistics collaboration helps smalland medium-sized companies to reduce costs, while increasing operational efficiency. In spite of these benefits, logistics collaboration encounters many challenges including partner search and selection, as well as trust management.

Academia and practitioners acknowledge that lack of trust hinders collaboration. Coincident to [3-5], lack of 
trust is a potential barrier to logistics collaboration. Graham [6] observed that lack of trust makes collaboration a difficult proposition to many companies. Such difficulties have largely been amplified by cloud computing, which is continuously elevating collaborative networks $(\mathrm{CNs})$ to a new level. Essentially, cloud computing and related technologies have transformed social-physical interaction systems, from traditional context to networked society. This transformation, on the one hand, supports global scale interaction of collaborating partners. On the other hand, emerged networked society has raised up difficulties on trust management. Illustratively, Falcone and Castelfranchi [7] have emphasized that success of computer-supported society in which humans cope with new kind of environments, procedures, and interactions is mainly dependent on trust and confidence. To that end, realizing trust a critical ingredient to logistics collaboration has become most imperative. Nevertheless, Ireland and Webb [8] have maintained that trust can build arrangements whereby firms contribute a minimum amount of resources to collaboratively achieve efficiency.

The remainder of the paper is structured in six sections. Section 2 presents a background on trust and behavioral uncertainties in CNs. Section 3 describes the state of the art and objectives of this review, while Sect. 4 presents a methodology this research applies. In Sect. 5, analysis and identification of issues influencing logistics collaboration and partner trust are presented. In Sect. 6, key behavioral factors and criteria are discussed and formalized. Finally, conclusion, implications, and outlook are provided in Sect. 7.

\section{Background}

Trust is studied in various disciplines like psychology, sociology, economics, computer science, and engineering. This multidisciplinary loop signifies how trust is critical to human life, especially upon considering countless interactions humans engage in. As trust is a multidisciplinary construct, its generalized theory remains unreached. As a consequence, definitions of trust in the literature are plentiful, largely compounded with contexts specific to applications. In computer science, according to Robinson et al. [9], trust has a context of security concerning the confidentiality, availability, and integrity of data or information. In social relational exchanges, trust has a form of reputation whose aim is to deny betrayal aversion. In economics, trust is associated with rational choices against risks. Alongside aforementioned contexts, the following are some of the trust definitions proposed in the literature. According to Gambetta [10], trust is the probability perceived by a trustor that a trustee will do something. According to Mayer et al. [11], trust is a willingness of a party to be vulnerable to actions of another party based on the expectation that other party will perform a particular action important to the trustor, irrespective of ability to monitor or control that other party. Rousseau et al. [12] define trust as a psychological state comprising the intention to accept vulnerability based upon positive expectations of the intentions or behavior of another. Nevertheless, according to Clark et al. [13], trust is the willingness of a party to accept perceived vulnerability to the actions of another party based on the expectation that the other has the ability, benevolence, and integrity to perform a particular action important to the trustor, irrespective of the ability to monitor or control that other party.

Concordant to CNs requirements, some definitions have limitations, while others are moderately adequate. The definition proposed by Rousseau et al. [12] poses a difficult in operationalizing psychological measurements even though remaining definitions emphasize on the willingness of the trustor-party to rely on the expectation that trusteeparty will act fairly. While willingness sounds to be more of psychology, in CNs, partner trust can better be described and represented under aspects of assurance, reliability, or confidence. To that end, consistent with trust definitions in $[11,13]$ and context specific to CNs, the following definition is adapted. That trust is a level of confidence trustorparty develops in trustee-party based on the expectation that trustee-party will perform a particular action necessary to trustor-party, irrespective of the ability to monitor or control trustee-party. This definition emphasizes more on a specific level of confidence, developed by a partner during trusting decisions. The definition applies to both, individual and organizational relationships. Partner trust applied to organizational relationships is referred to as the inter-organizational trust. According to Krishnan and Martin [14], inter-organizational trust is the expectation held by one firm that another will not exploit its vulnerabilities. This expectation, however, is uneasily achievable due to different behavioral uncertainties and resulting vulnerabilities.

In logistics collaboration, behavioral uncertainties contribute to the lack of trust. Such uncertainties can consistently be interpreted in accordance with Pfeffer and Salancik [15] as a degree to which future states of the world are difficult to anticipate and accurately predict. This difficulty makes an action to trust and decision making harder, but also uncertain. Decision-making uncertainty, according to Achrol and Stern [16], is operationalized to comprise of three concepts: (1) adequacy of available information from all sources; (2) predictability of the consequences of these decisions; and (3) the degree of confidence of the decision maker. Whereas information availability is limited, a difficulty in predicting trusteeparty's actions and interactions increases. As a result, trustor-party get exposed into unconfident trusting 
decisions. Equally considered, behavioral uncertainties attribute to opportunism [17] and are negatively and highly associated with firms' trust in supply chain relationships [18]. Thus, building on these arguments, it is claimed that level of trust can be increased by minimizing behavioral uncertainties. This claim is concordant to $\mathrm{Cao}$ and Zhang [19] who argue that logistics collaboration needs trust based rationalism that employs behavioral assumption of trustworthiness, fair play, and responsibility.

\section{Partner trust: the state of the art}

In the past and of recent, several publications have appeared to address trust under various domains of applications. Illustratively, in a CNs arena, roles and necessity of trust to overcome opportunism, selfish and alliance failure [20-23] have been examined. Measurement of trust [24-26], as well as partner selection strategies [27, 28], has been proposed even though Huang and Wilkinson [29] have affirmed that more literature on trust research has largely been of historical, processual, and contextual. They have additionally maintained in [30] that existing works have been static, cross-sectional, survey-based studies designed to develop and test variable-based correlational models in which time and process are least considered. As such, longitudinal investigations involving partners' trusting behaviors (actions and interactions) and respective performance are limited. This limitation is compounded with studying trust in the absence of a real problem, by which partners' trusting behaviors can be investigated. To overcome this, among others, it initially requires establishing behavioral factors which influence trust in logistics collaboration.

The literature has drawn the least attention to investigating behavioral factors and their consequences on partner trust. Factors affecting supply chain collaboration (SCC) [31] and level of trust [18] have been addressed. Equally, antidotes to dysfunctional behaviors, namely information sharing, decision synchronization, and incentive alignments [32], have been proposed. Together, these works contribute to requirements of functional supply chain and logistics collaboration. Beyond these requirements, trust difficulties resulting from uncertain behavioral aspects remain rarely investigated. Nevertheless, trust reviews in $[33,34]$ have emphasized on trust context and models, leaving out behavioral aspects. In essence, building trust in logistics collaboration may involve identifying behavioral factors and their influential mechanisms. Motivated by this need therefore, this review establishes behavioral factors influencing partner trust in the operational phase of logistics collaboration. The review fulfills three objectives: (1) establishing behavioral factors influencing logistics collaboration; (2) establishing how these factors influence partner trust; and (3) articulating criteria attributing to each factor.

\section{Methodology}

A systematic literature review (SLR) is applied to synthesize a new perspective on behavioral factors influencing partner trust. Appropriateness of SRL rests on its ability to bring together existing and relevant evidence-based studies [35], but also identifying key scientific contributions on a concerned topic [36]. Concordant to Denyer and Neely [37], SLR details how a study is conducted, thus inducing transparency and unbiasedness, and enabling readers to draw a reasonable and relevant conclusion. Moreover, according to Thorpe et al. [35], SLR offers broad coverage by applying systematic strings and protocols within sophisticated electronic databases.

\subsection{Review protocol}

This SLR follows stages proposed in [36], namely planning a review, conducting a review, and reporting and dissemination. Planning involves identifying, analyzing, and synthesizing behavioral factors influencing logistics collaboration and partner trust. It employs SCC and trust as topics. Correspondingly, five electronic databases to search in Science Direct, Wiley Online Library, Emerald, Springer, and IEEE are selected. These databases contain rich publications in the areas of logistics, supply chain, collaboration, and trust. Concurrent to a search process, a search strategy applies general and specific queries. General query is a form of a search question containing all search terms in one search string under single execution. The specific query contains few search terms executable sequentially under multiple options. General query is applied to databases supporting expert search, while the specific query is applied to remaining databases.

In conducting the review, three main search terms/ phrases identified are factors, "inter-organizational trust," and "supply chain collaboration." The terms are further expanded by including alternative and/or related terms, as well as by applying wildcard and truncation. In particular, the search:

- Term "factors" is expressed as impediments, impacts, barriers, challenges, uncertainties, and affecting. On applying wildcards, these search terms are expressed as factor ${ }^{*}$, imped $*$, impact* ${ }^{*}$, barrier*, challeng*, uncertaint*, and affect*;

- Phrase "inter-organizational trust" is expressed as trust and "inter-firm trust." Applying truncation to the 
search terms results in "organization" as "organi?ation";

- Phrase "supply chain collaboration" is expressed as collaboration, cooperation, "collaborative logistics," "cooperative logistics," "collaborative supply chain," "cooperative supply chain," "collaborative transportation," "cooperative transportation," "collaborative planning," and "cooperative planning." On applying wildcard, these search phrases are expressed as collaborat*, cooperat*, "collaborat* logistics," "cooperat* logistics," “collaborat* supply chain," "cooperat* supply chain," “collaborat* transport*," “cooperat* transport*," “collaborat* plan*," and “cooperat* plan*."

Subsequently, two main search queries are formulated. The first query includes a trust as search term, while the second query excludes it. Whereas results of the second query are likely duplicates, the intention is to capture factors which affect trust indirectly.

\subsection{Search process and results}

The search is executed in outlined databases using 20 search terms, resulting in a total of 2445 articles published between 2001 and 2015 inclusively. Firstly, the search process is executed by concentrating more on title, abstract, and keywords of articles. This concentration is preferred because body contents of articles are least specific to outlined topics compared to those in title, abstract, and keywords. Subsequently, inclusion and exclusion criteria are applied to screen actual relevance of articles. Beginning with practical screening, relevant articles are included based on how their titles, abstracts, and keywords address trust, inter-organizational systems, and supply chain and logistics collaboration. This screening filters previously 2445 articles obtained to 214 articles. Practical screening is followed by a methodological screening. Methodological screening emphasizes on the validity of research design, validity and reliability of data sources, and contextual meaning to the research subject. Additional to these criteria, articles which do not discuss impact/influence of supply chain, logistics, or performance on collaboration and/or trust are excluded. This screening is conducted by scrutinizing body contents of 214 articles. Finally, a total of 34 relevant articles (Table 1) are obtained.

\section{Analysis and identification of issues influencing partner trust}

Concerning partner trust in logistics collaboration, initial analysis of the literature reveals a total of ten issues (Table 2). However, despite an extent to which each issue is relevant, further analysis concentrating on behavioral perspective is conducted. The behavioral perspective centers on issues encompassing diverse set of partner's actions and interactions which feature during collaboration. Thus, along this perspective, each issue is briefly analyzed to establish a rationale whether it constitutes behavioral perspective or not.

Beginning with commitment, Morgan and Hunt [61] have defined relationship commitment as an exchange partner who believes that the ongoing relationship is worth working on to ensure that it endures indefinitely. Commitment is a key to social exchanges among collaborating parties even though a fundamental enquiry is whether commitment influences trust or trust influences commitment. In [18, 27], they established a positive relationship between trust level and degree of commitment, positing that trust influences commitment. Conversely, Seppanen et al. [62] have considered trusting a reciprocal construct, since it is both, a cause and partly an effect. Henceforth, on the one hand, the existence of trust can lead entities to develop more commitment. On the other hand, when entities perceive the existence of commitment, they even trust more. Contextual to logistics collaboration and in line with $[18,27]$, proposedly, trust influences commitment. This proposition is built on a consideration that, under normal interactive cues, entities have to establish trust before they get committed. Therefore, commitment is considered the least factor that can influence partner behaviors and trust.

The capability is mainly applied during partner search and selection. The capability is described by Tejpal et al. [33] as competence or work standard, skill, knowledge, and ability required to fulfill a promise, agreement, or obligation. In CNs, required capability is determined depending on collaboration stages, outlined in Pomponi et al. [3] as operational, tactical, and strategic. Particular to a theorybased framework in [3], each stage requires distinct mutual trust founded on appropriate theory. While behavioral uncertainties are dominantly in operational stage and least aligned to partner search and selection, qualifying capability as behavioral perspective is inappropriate.

Information sharing and communication appear wellknown issues in relation to collaboration and trust. According to Simatupang and Sridharan [58], information sharing is an act of capturing and disseminating timely and relevant information for decision makers to plan and control chain operations. Similarly, Cao and Zhang [42] defined communication as contact and message transmission process among partners in terms of frequency, direction, mode, and influence strategy. A critical enquiry is whether information sharing and/or communication can influence collaboration and trust. In the creation of the trust, Kottila and Rönni [63] claimed that high frequency of communication is not an indication of collaboration. With 
Table 1 Thematic description of articles reviewed

\begin{tabular}{|c|c|c|c|c|}
\hline Article & Journal & Domain & Study type & Main focus \\
\hline [38] & Logistics and SCM & Transportation & Theoretical & Chances and challenges of collaborative transport planning \\
\hline [39] & Ind Market Manag & Retailing & Survey & Role of inter-organizational information system (IOIS) integration \\
\hline [30] & J Bus Mark Manag & Business & Case study & $\begin{array}{l}\text { Conceptualize trust dimensions, processes, and determinants in } \\
\text { business relationships }\end{array}$ \\
\hline [23] & Inform Manage & Manufacturing & Survey & $\begin{array}{l}\text { Factors influencing information sharing and implementation } \\
\text { collaboration }\end{array}$ \\
\hline [40] & Oper Manag & Supply chain & Review & A typology of supply chain configurations \\
\hline [41] & Soc Behav Sci & $\begin{array}{l}\text { Resource } \\
\text { clustering }\end{array}$ & $\begin{array}{l}\text { Survey and } \\
\text { case study }\end{array}$ & $\begin{array}{l}\text { Examining the level of sharing matters generally and in a specific } \\
\text { cluster }\end{array}$ \\
\hline [42] & Oper Manag & Manufacturing & Survey & Nature of SCC and its impact on performance \\
\hline [43] & $\begin{array}{l}\text { Purchasing \& Supply } \\
\text { Manage }\end{array}$ & Manufacturing & Survey & $\begin{array}{l}\text { The construct of supply chain relationship quality and its influence on } \\
\text { cooperation }\end{array}$ \\
\hline [44] & WiCOM & Supply chain & Survey & Factors which influence SCC \\
\hline [45] & $\begin{array}{l}\text { Computers and Industrial } \\
\text { Engineering }\end{array}$ & Manufacturing & Survey & $\begin{array}{l}\text { Impact of trust, asset specificity, and environmental uncertainty on the } \\
\text { level of collaborative processes }\end{array}$ \\
\hline [46] & Manag Sci Eng Manag & Supply chain & Survey & $\begin{array}{l}\text { Dynamic dissimilar role of information sharing on dynamic trust and } \\
\text { cooperation }\end{array}$ \\
\hline [47] & System Sciences & Consumers & Survey & Antecedents of inter-organizational information sharing \\
\hline [18] & Suppl Chain Manage & Supply chain & Survey & Empirical testing of a relationship between trust and commitment \\
\hline [19] & Chapter in book & Manufacturing & Survey & Nature and characteristics, antecedents, and consequences of SCC \\
\hline [23] & Comp Stand Inter & Supply chain & Survey & $\begin{array}{l}\text { Role of information sharing, quality, and availability of trust in } \\
\text { collaboration }\end{array}$ \\
\hline [48] & $\mathrm{PhD}$ Thesis & Logistics & Experiment & Feasible collaboration model and mechanisms for horizontal logistics \\
\hline [49] & $\mathrm{PhD}$ Thesis & $\begin{array}{r}\text { Transport } \\
\text { logistics }\end{array}$ & $\begin{array}{l}\text { Case study and } \\
\text { survey }\end{array}$ & $\begin{array}{l}\text { Identification and exploration of components of horizontal cooperation } \\
\text { in logistics }\end{array}$ \\
\hline [6] & Technical Report & Transportation & Report & Barriers and benefits of transport collaboration \\
\hline [22] & Chapter in book & Supply chain & Simulation & Trust loop and its effect on performance \\
\hline [50] & Research Report & Transportation & Survey & $\begin{array}{l}\text { Understanding and developing less-than-truckload collaborative } \\
\text { paradigms }\end{array}$ \\
\hline [51] & $\begin{array}{l}\text { Management } \\
\text { Development }\end{array}$ & Supply chain & Review & $\begin{array}{l}\text { An integrated conceptual trust building model for supply chain } \\
\text { collaboration }\end{array}$ \\
\hline [33] & $\begin{array}{l}\text { Measuring Business } \\
\text { Excellence }\end{array}$ & Supply chain & Review & $\begin{array}{l}\text { Development of a context-dependent, multi-perspective and multilevel } \\
\text { concepts of trust }\end{array}$ \\
\hline [52] & Assembly Autom & Supply chain & Review & A review of the fundamental concept of collaborative supply chain \\
\hline [53] & $\begin{array}{l}\text { Qualitative Market } \\
\text { Research }\end{array}$ & Supply chain & Explanatory & $\begin{array}{l}\text { Understanding meanings, determinants and manifestations of trust in } \\
\text { supply chains }\end{array}$ \\
\hline [54] & White paper & Transportation & $\begin{array}{l}\text { Descriptive } \\
\text { analysis }\end{array}$ & $\begin{array}{l}\text { Collaborative transportation management concepts, benefits and } \\
\text { business case }\end{array}$ \\
\hline [55] & Marketing and Logistics & Supply chain & Survey & $\begin{array}{l}\text { The fit of the commitment-trust theory and exploration of the supply } \\
\text { chain relationships }\end{array}$ \\
\hline [56] & Prod Plan Control & Supply chain & $\begin{array}{l}\text { Review and } \\
\text { case study }\end{array}$ & $\begin{array}{l}\text { Analysis of collaborative motives and mechanisms of building } \\
\text { partnerships }\end{array}$ \\
\hline [31] & $\begin{array}{l}\text { Social \& Behavioral } \\
\text { Sciences }\end{array}$ & Supply chain & Review & Factors affecting collaboration in supply chain \\
\hline [57] & Benchmarking & Supply chain & Survey & Facets of supply chain trust and its multi-faceted measure \\
\hline [32] & Lect Notes Comput Sc & Supply chain & Review & Examining supply chain discontent in an integrative way \\
\hline [58] & Int J Phys Distrib & Supply chain & Survey & An instrument to measure the extent of collaboration in a supply chain \\
\hline [59] & Logistics Management & Supply chain & Theoretical & $\begin{array}{l}\text { Examining managerial inertia which prevents the effective functioning } \\
\text { of chain members }\end{array}$ \\
\hline [60] & Chapter in book & Logistics & Theoretical & $\begin{array}{l}\text { Contributions to collaborative logistics: Opportunities and main } \\
\text { coalition issues }\end{array}$ \\
\hline [27] & Business and Information & Transportation & Survey & $\begin{array}{l}\text { Exploring partner selection criteria during collaboration formation } \\
\text { stage }\end{array}$ \\
\hline
\end{tabular}


Table 2 Main issues arising from the literature

\begin{tabular}{|c|c|c|c|}
\hline No. & Issues & Articles & Definition \\
\hline 1 & Commitment & {$[22,44,53,57,64]$} & $\begin{array}{l}\text { An exchange partner believing that an ongoing relationship with another } \\
\text { is so important as to warrant maximum efforts at maintaining it [61] }\end{array}$ \\
\hline 2 & Capability & {$[33,51,53]$} & $\begin{array}{l}\text { The members' competence or work standard, skill, knowledge, and ability } \\
\text { to fulfill a promise, agreement, or obligation [33] }\end{array}$ \\
\hline 3 & $\begin{array}{l}\text { Information } \\
\text { sharing }\end{array}$ & {$[18,23,31,32,42,46,47,53-55,58,64]$} & $\begin{array}{l}\text { The act of capturing and disseminating timely and relevant information } \\
\text { for decision makers to plan and control supply chain operations [32] }\end{array}$ \\
\hline 4 & Communication & {$[42,43]$} & $\begin{array}{l}\text { The contact and message transmission process among supply chain } \\
\text { partners in terms of frequency, direction, and mode [42] }\end{array}$ \\
\hline 5 & $\begin{array}{l}\text { Asset } \\
\text { specificity }\end{array}$ & {$[18,45]$} & $\begin{array}{l}\text { Transaction-specific investments involving physical or human assets that } \\
\text { are dedicated to a particular relationship and cannot be redeployed easily } \\
\text { [65] }\end{array}$ \\
\hline 6 & $\begin{array}{r}\text { Resource } \\
\text { sharing }\end{array}$ & [42] & $\begin{array}{l}\text { The process of leveraging capabilities and assets and investing in } \\
\text { capabilities and assets with supply chain partners [42] }\end{array}$ \\
\hline 7 & $\begin{array}{l}\text { Joint } \\
\text { knowledge } \\
\text { creation }\end{array}$ & {$[42]$} & $\begin{array}{l}\text { The extent to which supply chain partners develop a better understanding } \\
\text { of and response to the market and competitive environment by working } \\
\text { together }[42,66]\end{array}$ \\
\hline 8 & $\begin{array}{l}\text { Incentive } \\
\text { alignment }\end{array}$ & {$[32,38,42,48-50,56,59]$} & $\begin{array}{l}\text { The process of sharing costs, risks, and benefits among supply chain } \\
\text { partners [31] }\end{array}$ \\
\hline 9 & $\begin{array}{l}\text { Bargaining } \\
\text { power }\end{array}$ & {$[18,32,44,48,49,57,64]$} & $\begin{array}{l}\text { The ability of a person, group, or organization to exert influence over } \\
\text { another party in order to influence the outcome of the negotiation and to } \\
\text { achieve a favorable deal [48] }\end{array}$ \\
\hline 10 & Opportunism & {$[22,31,33,38,40,44,49,52,55,57]$} & $\begin{array}{l}\text { A particular form of inconsistency of purpose, involving disclosure of } \\
\text { incomplete/misleading information, especially calculated efforts to } \\
\text { mislead, distort, disguise, confuse, or cause confusion [22] }\end{array}$ \\
\hline
\end{tabular}

this viewpoint, partner behaviors can better be described and represented from the perspective of information sharing than communication.

Asset specificity, resource sharing, and joint knowledge creation are necessary issues in collaboration. According to Heide [65], asset specificity is a transaction-specific investment involving physical or human assets, dedicated to a particular relationship and which cannot be redeployed easily. According to Cao and Zhang [42], resource sharing refers to the process of leveraging capabilities and assets and investing in capabilities and assets with supply chain partners. Essentially, these concepts drive entities to collaborate, when underlying resources are difficult to redeploy. Moreover, Cao and Zhang [42] and Malhotra et al. [66] explained joint knowledge creation as the extent to which supply chain partners develop a better understanding of and response to the market and competitive environment by working together. Examining these issues together, asset specificity and resource sharing are least related to partner behaviors but an investment. As such, it is inappropriate to represent partner behaviors in the perspective of investment. Concerning joint knowledge, while partner behaviors are dominant in operational stage, joint knowledge creation focuses more on strategic stage. Equally, it is inappropriate to qualify joint knowledge creation under behavioral perspective.

Incentive alignment, bargaining power, and opportunism are widely stated in the literature as major issues influencing collaboration and trust. In line with Hudnurkar [31], incentive alignment concerns the allocation of costs, risks, and benefits among partners. Xu [48] has discussed bargaining power as the ability of a party to exert influence over another party and influence the outcome of the negotiation. Moreover, Ouzrout et al. [22] refer to opportunism as a particular form of the inconsistency of purpose. These three issues are key to logistics collaboration, and they represent diverse aspects by which partner behaviors can be described.

\section{Discussions}

This section synthesizes and subsequently presents detailed discussions on selected behavioral factors which influence logistics collaboration and partner trust. Subsequent to brief analysis in Sect. 5, discussions are categorized under four behavioral themes: information sharing, incentive alignment, decision synchronization, and opportunism (Table 3).

\subsection{Information sharing}

Information sharing denotes an information exchange. This exchange, according to Madlberger [47] is a voluntary activity dominated largely by internal considerations. As such, understanding criteria which influence behavioral practices associated with information exchange is a 
Table 3 Summary of behavioral factors and criteria influencing partner trust in logistics collaboration

\begin{tabular}{|c|c|c|c|}
\hline References & Factor & Criteria & Definition \\
\hline \multirow[t]{5}{*}[18,23,31,32,42,46,47,53-55,58,64]{} & \multirow{5}{*}{$\begin{array}{l}\text { Information } \\
\text { sharing }\end{array}$} & Timeliness & Partners exchange information on time \\
\hline & & Relevancy & Partners exchange relevant and reliable information \\
\hline & & Accuracy & Partners exchange accurate information \\
\hline & & Confidentiality & Partners exchange proprietary or confidential information \\
\hline & & Completeness & Partners exchange complete and adequate information \\
\hline \multirow[t]{3}{*}[32,38,42,48-50,56,59,60]{} & \multirow{3}{*}{$\begin{array}{l}\text { Incentive } \\
\text { alignment }\end{array}$} & Cost allocation & Partners share costs of collaboration fairly \\
\hline & & $\begin{array}{l}\text { Savings } \\
\text { allocation }\end{array}$ & Partners share benefits of collaboration fairly \\
\hline & & Risks allocation & Collaborating partners share any risks that can occur \\
\hline \multirow[t]{2}{*}[18,32,48,49,57]{} & \multirow[t]{2}{*}{$\begin{array}{l}\text { Decision } \\
\text { synchronization }\end{array}$} & $\begin{array}{l}\text { Perceived } \\
\text { conflict }\end{array}$ & A degree of disagreement over domain of decision \\
\hline & & $\begin{array}{l}\text { Bargaining } \\
\text { power }\end{array}$ & $\begin{array}{l}\text { The ability of a party to exert influence over others for } \\
\text { influencing the outcome of the negotiation }\end{array}$ \\
\hline \multirow[t]{3}{*}[22,31,33,38,40,49,52,55,57]{} & \multirow[t]{3}{*}{ Opportunism } & Claim of shares & $\begin{array}{l}\text { A behavior that the partner claims either fair or unfair share } \\
\text { of the value created }\end{array}$ \\
\hline & & $\begin{array}{l}\text { Usage of } \\
\text { alliance } \\
\text { resources }\end{array}$ & $\begin{array}{l}\text { Fair or unfair usage of alliance resources to create a value } \\
\text { outside of the alliance }\end{array}$ \\
\hline & & $\begin{array}{l}\text { Proprietary } \\
\text { information }\end{array}$ & $\begin{array}{l}\text { Fair or unfair usage of proprietary or confidential } \\
\text { information for individual partner's benefit }\end{array}$ \\
\hline
\end{tabular}

necessary [23]. Such behavioral practices can appear in opponent facets, termed as beneficial or detrimental. Beneficial facet involves exchanging information that conforms to requirements standards of consortia, while detrimental ones appear lacking this compliance. To categorize these facets, one has to consider identifying information exchange rituals partner exhibit during collaboration. Such rituals can fundamentally be associated with criteria defining quality information, as conveyed signals are foundationally assessed depending on their quality (Table 3).

This analysis characterizes quality information to comprise of four criteria: timeliness [23, 42, 46], relevance [23, 42], accuracy [23, 42, 46], and completeness [23, 42, 46]. These criteria emphasize on the on-time availability of reliable data, rich enough to meet consumer's needs. In addition, such data must represent a fact on business reality and provide adequate interpretation in a context intended. While these criteria emphasize as well on information visibility, consequently, it means information has to be trustworthily available on-time and able to elucidate users' requirement. Furthermore, exchanged information can be proprietary and confidential [23, 42, 53, 54, 67].

Information exchange practices can influence trust in both negative and positive ways. In particular, untimely, irrelevant, inaccurate, and incomplete information can escalate uncertainty, signaling a deviation from the agreement. Conversely, exchanging timely, relevant, accurate, and complete information, signals compliance to collaboration agreements. Therefore, it appears that trust can be granted and promoted if partners exchange quality information even though a choice to exchange quality or poor information remains within partners. Therefore, information sharing can influence partner trust depending on actual character exhibited by partners.

\subsection{Incentive alignment}

Associated with dividing costs, gains, and risks, in [19, 42] they consider incentive alignment as concerns on the formulation of incentive schemes. According to Simatupang and Sridharan [32], proper incentives motivate partners to align individual decision making more closely to the overall goal. Meanwhile, Wang and Kopfer [38] have asserted that identifying contributions of each partner to the coalition is difficult. While Xu [48] and D'Amours and Rönnqvist [60] have emphasized on simple rules of thumb that distribute savings proportionally, Tseng et al. [68] have proposed a general framework for designing compensation rule. The framework seems reasonable as it takes into account three crucial aspects: (1) elements to be compensated; (2) how to compensate; and (3) criteria to evaluate compensation. A challenge remains to an extent to which these rules are fairly acceptable. It has been established that it is difficult to determine potential cost savings $[38,49]$ as well as ensuring a fair allocation of the shared workload in advance [6]. Overall, despite proposed sharing 
schemes (proportional and Shapley value) and the general framework, evidence on their practical application and acceptance is lacking. As a consequence, it is claimed in [49] that many logistics collaboration initiatives disintegrate because of mistrust about the fairness of these rules.

Associated with behavioral uncertainty, an essential requisite centers on synthesizing how incentive schemes affect partner trust. It can be established that incentive schemes influence partner trust depending a degree of fairness partners perceive. Unfair allocation of incentives can increase trust uncertainties because of suspiciousness and rivalry in unseen returns. Conversely, upon realizing fairness in the sharing of pains and gains by means of evenhanded negotiations [54, 57], trust can be promoted. Therefore, considering incentive scheme, three criteria "costs allocation" [48, 49, 57], "savings allocation" $[38,49]$, and "risks allocation" [42, 49] are formalized.

\subsection{Decision synchronization}

Simatupang and Sridharan [59] refer to decision synchronization as a process by which partners coordinate planning and operations activities to optimize benefits. It comprises of joint exercising and redesigning of decision rights [32]. As noted in [18], decision synchronization helps to resolve conflicts or disagreement. Preference partners assume on decision rights can generate equivalent effects on trust. Depending on the outcome, this effect either strengthens or weakens collaboration and partner trust. For example, upon deciding in favor of own interests, a partner will mostly end up denying welfare others. Illustratively, in shipper-receiver collaboration, the shipper may perceive producing goods in fixed quantities, while receiver may perceive a production which is consistent with demand. In this and similar cases, owner of a specific decision right has to reconsider effects of its decision on other partners and entire consortium. Following this requirement, differences in preferences must be synchronized to a balance. This synchronization proceeds, thereby moderating conflicting positions to a specific decision right for a purpose of building trust.

Cruijssen [49] established that decision synchronizations are vital to situations in which actions and decisions by one partner often create uncompensated costs or benefits to others. According to [32], the unsynchronized decision appears in two behavioral discontents rivalry and compromise described as follows. With rivalry behavior, a party has high concern for its own interest coupled with low concern for the other parties' interests (I win, you lose); with compromise behavior, a party emphasizes on give-and-take bargaining to split cost savings during the relationship (we both win $a$ bit and lose a bit). Aiming to build trust, partners have to moderate decision rights toward the compromise style which appears satisfactory and acceptable. To conclude, perceived conflict [18, 49] and bargaining power [49] are criteria constituting decision synchronization, which in turn, affect partner trust.

\subsection{Opportunism}

Opportunism involves guileful behaviors seeking to maximize self-profits or artfully egoism that pursue profits [44]. Williamson [17] views opportunism as an incomplete or distorted disclosure of information. Contrary to opportunism is a goal congruence, described in [40] as a degree to which parties perceive their own goals to be satisfied. Such goals are satisfied when partners recognize fairness to collaboration and upon recognizing that they are unexploited.

In logistics collaboration, the level of trust can be increased by minimizing opportunism. Building trust by minimizing opportunism requires identifying criteria prescribing behavioral practices partners exhibit. Analysis and synthesis of the literature have revealed three criteria, namely the unfair claim of shares [52], improper usage of alliance resources [38, 42], and misuse of proprietary information [49]. Furthermore, opportunism and goal congruence can generate opposing effects on collaboration and trust. The existence of opportunism seems to lessen the level of trust, especially when a degree of self-interests exceeds that of perceived congruence. Partners acting opportunistically brings in a win-lose dilemma in place of compromise and competition in place of cooperation. As a result, the level of trust can decline due to partners being more suspicious. However, when partners behave alongside true goal congruence, a sense of harmony, compromise, and collective responsibility can prevail.

\section{Conclusion, implications, and outlook}

Establishing and sustaining CNs consortia appears difficult due to many impediments, of which lack of partner trust is prominent. The lack of partner trust is contributed mainly by partners' behavioral uncertainties coupled to logistics collaborative processes. While previous research has attempted to mitigate mistrust problem, little attention has been paid to behavioral trust in logistics collaboration. In its entirety, behavioral trust comprises of partner's actions and interactions occurring during collaboration, and whose outcome can predictively be estimated. Toward this requirement, therefore, an initial aim was to establish behavioral aspects which influence partner trust. To that end, using SLR, the present paper has succeeded to reveal key behavioral factors (collaborative processes). The factors are information sharing, incentive alignment, decision synchronization, and opportunism. Additionally, this SLR has managed to offer a new perspective concerning the 
influence of behavioral factors and associated criteria on partner trust in logistics collaboration. Nevertheless, revealed factors constitute operational success and measurable criteria necessary for empirical investigation, especially by means of appropriate experiments.

This review has drawn many useful implications to both, practitioners and academia. To practitioners, trust building in logistics collaboration must be supported with auspicious and certain behavioral practices. Although acting against this requirement may offer one-time benefits, yet there can be long-term disadvantages due to negative recurring experiences. Since behavioral trust is built through repetitive interactions, individual and firms are implicated to observe on uncertainties associated with behavioral factors. To that end, individuals and firms inspiring to collaborate or already collaborating are urged to care on how they exchange information, allocate incentives, compromise conflicting preferences, and minimize opportunism.

On the whole, the present paper has provided thorough review, findings, and implications concerning behavioral factors which influence partner trust in logistics collaboration. While this is true, an acknowledgment of limitations of this study is provided. Firstly, whereas trust in logistics collaboration is also affected by non-behavioral factors, this review concentrated on behavioral ones because they are closely aligned to operational stage requirements. Secondly, applied SLR may have left out some works in databases which were not specified in review protocol. Following this limitation, it is acknowledged that synthesized behavioral factors may not be universally exhaustive.

To academia, this review has thrown future works, especially on the empirical estimation of an extent to which factors affect trustworthiness. Correspondingly, such empirical works have to take care of time and process, meanwhile featuring realism through case study and/or virtual experimentation. This investigation has to determine effects resulting from both, certain and uncertain behavioral factors, and observe emergent phenomena. Finally, the investigation may also examine a combined effect of the factors on partner trust.

Acknowledgments The corresponding author would like to acknowledge the support of the Ministry of Education and Vocation Training (MoEVT-Tanzania) and the German Academic Exchange Service (DAAD) under the Tanzania-Germany Postgraduate Training Programme.

\section{Compliance with ethical standards}

Conflict of interest The authors declare that they have no conflict of interest.

Open Access This article is distributed under the terms of the Creative Commons Attribution 4.0 International License (http://crea tivecommons.org/licenses/by/4.0/), which permits unrestricted use, distribution, and reproduction in any medium, provided you give appropriate credit to the original author(s) and the source, provide a link to the Creative Commons license, and indicate if changes were made.

\section{References}

1. Kayikci Y, Stix V (2014) Causal mechanism in transport collaboration. J Expert Syst Appl 41(4):1561-1575

2. Wang X, Kopfer H (2014) Collaborative transportation planning of less-than-truckload freight. OR Spectr 36(2):357-380

3. Pomponi F, Fratocchi L, Tafuri SR (2015) Trust development and horizontal collaboration in logistics: a theory based evolutionary framework. J Suppl Chain Manag 20(1):83-97

4. Taneja M, Kalita D (2014) Partnering with competitors to reduce logistics costs. The smart cube. http://www.thesmartcube.com/ insights/blog/blog-details/insights/2014/11/11/partnering-withcompetitors-to-reduce-logistics-costs. Accessed 12 May 2015

5. Baalsrud Hauge J, Kalverkamp M, Forcolin M et al (2014) Collaborative Serious Games for Awareness on Shared Resources in Supply Chain Management. In: Grabot B, Vallespir B et al (eds) Advances in Production Management Systems. Innovative and Knowledge-Based Production Management in a Global-Local World. Springer, Heidelberg, pp 491-499

6. Graham L (2011) Transport collaboration in Europe. Technical Report, ProLogis Corporate. http://www.prologis.com/docs/ research/europe/Transportation_Collaboration-finalrev.pdf. Accessed 17 Feb 2015

7. Castelfranchi C, Falcone R (2004) Trust dynamics: how trust is influenced by direct experiences and by trust itself. In: AAMAS 2004, New-York, IIE

8. Ireland RD, Webb JW (2007) A multi-theoretic perspective on trust and power in strategic supply chains. J Oper Manag 25(2):482-497

9. Robinson R, Valeri L, Cave J et al (2011) The cloud: understanding the security, privacy and trust challenges. RAND Corporation, California

10. Gambetta DG (1988) Can We Trust Trust? In: Gambetta DG (ed) Trust. Blackwell, New York, pp 213-237

11. Mayer RC, Davis J, Schoorman FD (1995) An integrative model of organizational trust. Acad Manag Rev 20(3):709-734

12. Rousseau DM, Sitkin SB, Burt RS et al (1998) Not so different after all: a cross-discipline view of trust. Acad Manag Rev 23(3):393-404

13. Clark WR, Ellen PS, Boles JS (2010) An examination of trust dimensions across high and low dependence situations. J Bus-Bus Mark 17(3):215-248

14. Krishnan R, Martin X (2006) When does trust matter to alliance performance? Acad Manag Rev 49(5):894-917

15. Pfeffer J, Salancik G (1978) The external control of organizations. Harper and Row, New York

16. Achrol RS, Stern LW (1988) Environmental determinants of decision-making uncertainty in marketing channels. J Mark Res 25(1):36-50

17. Williamson OE (1985) The economic institutions of capitalism. The Free Press, New York

18. Kwon IWG, Suh T (2004) Factors affecting the level of trust and commitment in supply chain relationships. J Supply Chain Manag 40(2):4-14

19. Cao M, Zhang Q (2013) Supply Chain Collaboration Roles of Interorganizational Systems, Trust, and Collaborative Culture. Springer, London

20. Jones SL, Fawcett SE, Wallin C et al (2014) Can small firms gain relational advantage? Exploring strategic choice and 
trustworthiness signals in supply chain relationships. Int J Prod Res 52(18):5451-5466

21. Hossain SA, Ouzrout Y (2012) Trust model simulation for supply chain management. Comput Inf Technol (ICCIT). doi:10.1109/ ICCITechn.2012.6509744

22. Ouzrout Y, Chaze L, Lavastre O et al (2010) Simulation of trust in supply chains. In: Botta-Genoulaz V et al (eds) Supply chain performance. Wiley, Hoboken, pp 267-315

23. Chen JV, Yen DC, Rajkumar TM, Tomochko NA (2011) The antecedent factors on trust and commitment in supply chain relationships. J Comput Stand Interfaces 33(3):262-270

24. Laeequddin M, Sahay BS, Sahay V et al (2010) Measuring trust in supply chain partners' relationships. J Meas Bus Excell 14(3):53-69

25. Ha BC, Park YK, Cho S (2011) Suppliers' affective trust and trust in competency in buyers. Int J Oper Prod Manag 31(1):56-77

26. Söllner M, Hoffmann A, Hirdes EM et al (2010) Towards a formative measurement model for trust. In: 23rd Bled eConference eTrust: Implications for the Individual, Enterprises and Society (Bled)

27. Asawasakulsorn A (2009) Transportation collaboration: partner selection criteria and IOS design issues for supporting trust. Int $\mathbf{J}$ Bus Inf 4(2):199-220

28. Seifert M (2007) Collaboration formation in virtual organizations by applying prospective performance measurement. Dissertation, University of Bremen

29. Huang Y, Wilkinson IF (2013) The dynamics and evolution of trust in business relationships. J Ind Mark Manag 42(3):455-465

30. Huang YS, Wilkinson IF (2014) A case study of the development of trust in a business relation: implications for a dynamic theory of trust. J Bus Mark Manag 7(1):254-279

31. Hudnurkar M, Jakhar S, Rathod U (2014) Factors affecting collaboration in supply chain: a literature review. Proc Soc Behav Sci 133:189-202

32. Simatupang TM, Sridharan R (2005) Supply chain discontent. J Lect Notes Comput Sci 11(4):349-369

33. Tejpal G, Garg RK, Sachdeva A (2013) Trust among supply chain partners: a review. Meas Bus Excell 17(1):51-71

34. Adams BD, Flear C, Taylor TE et al (2010) Review of interorganizational trust models. Human systems incorporated. http:// www.dtic.mil/dtic/tr/fulltext/u2/a537389.pdf. Accessed 13 July 2015

35. Thorpe R, Holt R, Macpherson A et al (2005) Using knowledge in small and medium sized firms: a systematic review of the evidence. Int J Manag Rev 7(4):257-282

36. Tranfield D, Denyer D, Smart P (2003) Towards a methodology for developing evidence-informed management knowledge by means of systematic review. Br J Manag 14:207-222

37. Denyer D, Neely A (2004) Introduction to special issue: innovation and productivity performance in the UK. Int J Manag Rev 5(6):131-135

38. Wang X, Kopfer H (2011) Increasing efficiency of freight carriers through collaborative transport planning: chances and challenges. In: Ivanov D et al (eds) Dynamics and sustainability in international logistics and supply chain management. Proceedings of the 6th German-Russian logistics and SCM workshop, pp 41-50

39. Rajaguru R, Matanda MJ (2013) Effects of inter-organizational compatibility on supply chain capabilities: exploring the mediating role of inter-organizational information systems (IOIS) integration. J Ind Mark Manag 42(4):620-632

40. Lejeune MA, Yakova N (2005) On characterizing the 4 C's in supply chain management. J Oper Manag 23(1):81-100

41. Otčenášková T, Kolerová K, Bureš V (2014) Sharing of resources: theoretical background and a case study. Proc Soc Behav Sci 109:698-705
42. Cao M, Zhang Q (2011) Supply chain collaboration: impact on collaborative advantage and firm performance. J Oper Manag 29(3): 163-180

43. Su Q, Song Y, Li Z, Dang J (2008) The impact of supply chain relationship quality on cooperative strategy. J Purch and Supply Manag 14(4):263-272

44. Tao C, Zhe P (2007) A study on influential factors of supply chain alliance relationship of Chinese WiCOM, International Conference, pp 4776-4781

45. Jeng DJ, Mortel CHA (2010) Impact of trust, asset specificity, and environmental uncertainty on manufacturing collaborative processes. Computers and industrial engineering (CIE), 40th International Conference, pp 1-7

46. Ming Y, Song-zheng Z (2008) Information sharing as antecedent of dynamic trust and cooperation intention in supply chain: evidence from China, management science and engineering. 15th Annual Conference Proceedings, pp 298-305

47. Madlberger M (2008) inter-organizational collaboration in supply chain management: what drives firms to share information with their trading partners? Proceedings of the 41st Hawaii International Conference on System Sciences, pp 1-10

48. Xu X (2013) collaboration mechanism in the horizontal logistics collaboration. Dissertation, Ecole Nationale Supérieure des Mines de Paris

49. Cruijssen FCAM (2006) Horizontal cooperation in transport and logistics. Dissertation, Tilburg University

50. Peeta S, Hernandez S (2011) Modeling of collaborative less-thantruckload carrier freight networks. USDOT Region V Regional University Transportation

51. Laeequddin M, Sahay BS, Sahay V, Waheed KA (2012) Trust building in supply chain partners relationship: an integrated conceptual model. J Manag Dev 31(6):550-564

52. Mehrjerdi YZ (2011) The collaborative supply chain. Assem Autom 29(2):127-136

53. Skandrani H, Triki A, Baratli B (2011) Trust in supply chains, meanings, determinants and demonstrations. Qual Mark Res Int J 14(4):391-409

54. CIM sub-committee of the voluntary inter-industry commerce standards (VICS) Logistic committee (2004) collaborative transportation management white paper, Version 1.0. http://www. vics.org. Accessed 17 Dec 2014

55. Wu MY, Weng YC, Huang IC (2012) A study of supply chain partnerships based on the commitment-trust theory. Asia Pac J Mark Logist 24(4):690-707

56. Lehoux N, D'Amours S, Langevin A (2014) Inter-firm collaborations and supply chain coordination: review of key elements and case study. J Prod Plan Control 25(10):858-872

57. Jones SL, Fawcett SE, Fawcett AM et al (2010) Benchmarking trust signals in supply chain alliances: moving toward a robust measure of trust. Benchmarking Int J 17:705-727

58. Simatupang TM, Sridharan R (2005) The collaboration index: a measure for supply chain collaboration. Int J Phys Distrib 35(1):44-62

59. Simatupang TM, Sridharan R (2002) The collaborative supply chain. Int J Logist Manag 13(1):15-30

60. D'Amours S, Rönnqvist M (2010) Issues in collaborative logistics. In: Bjørndal E, Bjørndal M, Pardalos PM, Rönnqvist M (eds) Energy, natural resources and environmental economics. Springer, Berlin, Heidelberg, pp 395-409

61. Morgan RM, Hunt SD (1994) The commitment-trust theory of relationship marketing. J Mark 58(3):20-38

62. Seppanen R, Blomqvist K, Sundqvist S (2007) Measuring interorganizational trust - a critical review of the empirical research in 1990-2003. Ind Mark Manag 36:249-265

63. Kottila MR, Rönni P (2008) Collaboration and trust in two organic food chains. Br Food J 110(4/5):376-394 
64. Wu IL, Chuang CH, Hsu CH (2014) Information sharing and collaborative behaviors in enabling supply chain performance: a social exchange perspective. Int J Prod Econ 148:122-132

65. Heide JB (1994) Interorganizational governance in marketing channels. J Mark 58:71-85

66. Malhotra A, Gasain S, El Sawy OA (2005) Absorptive capacity configurations in supply chains: gearing for partner-enabled market knowledge creation. MIS Q 29(1):145-187
67. Cheng JH (2011) Inter-organizational relationships and information sharing in supply chains. Int J Inf Manag 31(4):374-384 68. Tseng MM, Yan J, Cruijssen F (2013) Position paper on compensation rules. Collaboration concepts for co-modality. http:// www.co3-project.eu/wo3/wp-content/uploads/2011/12/CO3-D-25-Position-Paper-on-Compensation-Rule.pdf. Accessed $29 \mathrm{Mar}$ 2016 